\title{
A descriptive study of cranio-cerebral injuries admitted in tertiary care center of coastal Andhra Pradesh
}

\author{
R. Sivakumar ${ }^{1}$, B.V. Subrahmanyam ${ }^{1}$, S.V. Phanindra ${ }^{1}$, Ashok \\ Munivenkatappa $^{2}$, S. Satish Kumar ${ }^{3}$, Amit Agrawal ${ }^{4}$
}

${ }^{1}$ Forensic Medicine, Department of Forensic Medicine, Narayana Medical College Hospital, Chinthareddypalem, Nellore, Andhra Pradesh, INDIA

${ }^{2}$ National Institute of Epidemiology, ICMR, Chennai - 77, Tamil Nadu, INDIA

${ }^{3}$ Emergency Medicine, Department of Emergency Medicine, Narayana Medical College Hospital, Chinthareddypalem, Nellore, Andhra Pradesh, INDIA

${ }^{4}$ Department of Neurosurgery, Narayana Medical College Hospital, Chinthareddypalem, Nellore, Andhra Pradesh, INDIA

\begin{abstract}
Introduction: Demographic and clinical profile of traumatic brain injury (TBI) of a particular place is very crucial for strengthening the guidelines. The details of same are scant from a tertiary institute, Nellore district. The present study aims to explore the demographic, injury and clinical aspects of cerebro-cranial injury patients from an institute setup. Methods: The study consists of two years retrospective data and one year prospective data. The study was approved by institute ethical committee. The patient data was entered on pre designed proforma that includes the desired variables. The data analysis was done using StatsDirect software. Both prospective and retrospective data was merged for analysis. Percentages for categorical data and mean values for continuous data were calculated. Results: There were total of 336 patients. Patients in age group of 21 to 50 years constituted $67 \%$ and males were four times higher than females. Nearly one fourth of patients were influenced by alcohol. Three fourth of accidents were due to road traffic accidents (RTAs) followed by falls (17\%) and assault (6\%). About one tenth of patients were pedestrians. One fourth of patients had associated injuries other than head and brain. On CT findings majority of patients had cerebral contusion (46\%) followed by skull fracture (40\%), SDH (28\%) and EDH (23\%). Twenty two patients died in the study period. Conclusion: Knowledge of injury and its later consequences to public is very important. Strict rules to consider safety precautions and compulsory family insurances should be encouraged. Rules to prevent paediatric drive.
\end{abstract}

Key words: Age, gender, TBI, institute, CT findings, urban, RTA, guidelines 


\section{Introduction}

Traumatic brain injury (TBI) has long been recognized as a leading cause of mortality and permanent neurological disability worldwide and has been described as a silent and causing a significant social and financial burden for them, their families and the public health system. [1] In year 2014 The National Crime Report Bureau reported that there were a total of 4,81,805 traffic accidents and out of these 4,50,898 were road accidents which were responsible for $1,41,526$ deaths. [2] In India, road traffic injuries projected to become the second leading cause of death by the year 2020. [3] There are few studies from India that have described the epidemiology of TBI and discussed related issues, including the need for public awareness campaigns and enforcement of legislation to reduce the number of injuries. [4-8] Most of these studies have been conducted in different parts of country at institute level and the present study is aimed to describe epidemiological characteristics, pattern of injuries and related clinical parameters of TBI from a tertiary care setup located in the coastal area of southern India.

\section{Materials and Methods}

Narayana Medical College and General Hospital is a multi and super specialty hospital located in costal Andhra district, Nellore. It is a three years study that included data from 2011 to 2014. The study was approved by Institute Ethical Board. The data was collected on a standard proforma. The proforma includes details of age, sex, causes of head injury, pattern of head injuries, Computer Tomography (CT) findings like skull fractures, parenchymal injuries, intracranial hemorrhages, and discharge outcome (alive or death).

\section{Statistical analysis}

The data analysis was done using StatsDirect version 3.0.150 (StatsDirect statistical software. http://www.statsdirect.com. England: 2015). For analysis both retrospective and prospective data was combined together. Percentages were calculated for categorical data, and mean, standard deviation was calculated for continuous data.

\section{Results}

During study period there were 336 cases, of them 116 were prospective and 220 were retrospective cases. The mean age was $35.05 \pm$ 16.36 years. Sixty seven percent of patients were in 3rd, 4th and 5th decade of age group (figure 1). Males were four times more than females. About $50 \%$ of patients were from urban setup. Sixty six percent of injuries occurred on road. About 75 patients (22.3\%) were influenced by alcohol (Table-1). 
Table 1 - Demographic variable of cranio cerebral injury patients

\begin{tabular}{|l|l|}
\hline Variables & $\mathbf{n}(\%)$ \\
\hline Age (years) & $35.05 \pm 16.36$ \\
\hline Gender \\
\hline Male & $269(80)$ \\
\hline Female & $67(20)$ \\
\hline Location of injury \\
\hline Urban & $169(50.3)$ \\
\hline Rural & $167(49.7)$ \\
\hline Place of injury \\
\hline Road & $224(66.7)$ \\
\hline Home & $47(14)$ \\
\hline Streets & $25(7.4)$ \\
\hline Fields & $11(3.3)$ \\
\hline Others & $29(8.6)$ \\
\hline Alcohol influence \\
\hline Yes & $75(22.3)$ \\
\hline
\end{tabular}

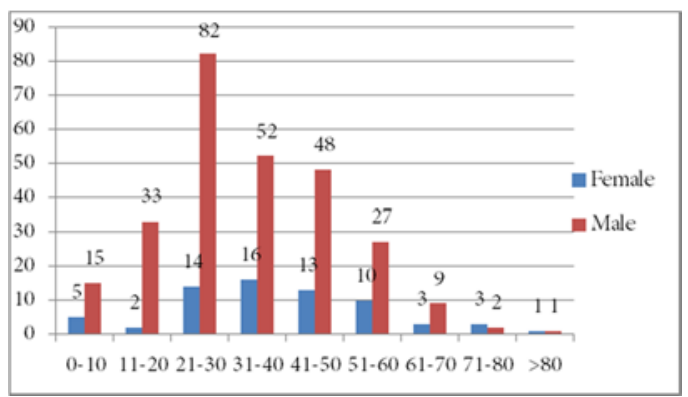

Figure 1 - Decade wise distribution of TBI patients

Road Traffic Accidents (RTAs) was major cause of injury accounting for $75.6 \%$, followed by falls (17.9\%) and assault (6\%). Among RTAs the motorcycle victim was affected in higher number (42.3\%) followed by motor vehicle driver (15.2\%) and pedestrian (12.2\%). None of two wheelers worn helmet while riding vehicle. Two wheeler was most common victim vehicle $(54.8 \%)$ followed by four wheeler $(4.8 \%)$ and three wheeler (4.5\%). Associated injuries were present among $23.3 \%$ of patients (Table-2).

Table 2 - Details of mode and associated injuries among traumatic brain injury

\begin{tabular}{|l|l|}
\hline Variables & n (\%) \\
\hline Cause of injury & $254(75.6)$ \\
\hline Road Traffic Accident (RTA) & $60(17.9)$ \\
\hline Fall & $20(6)$ \\
\hline Assault & $2(0.6)$ \\
\hline Object fall & \multicolumn{2}{|l|}{} \\
\hline Accident victim among RTA \\
\hline Motorcycle rider & $142(42.3)$ \\
\hline Motor vehicle driver & $51(15.2)$ \\
\hline Pedestrian & $41(12.2)$ \\
\hline Passenger & $20(6)$ \\
\hline Associated injuries - present \\
\hline Extremities fracture & $45(13.4)$ \\
\hline Lung and Pleura & $11(3.2)$ \\
\hline Cervical spine & $21(6.3)$ \\
\hline Dorsal spine & $1(0.3)$ \\
\hline External injuries of head \\
\hline Scalp & $278(82.7)$ \\
\hline Face & $213(63.4)$ \\
\hline
\end{tabular}

On CT findings; $40 \%$ of patient had skull fractures. Among intra cranial brain lesion, brain contusion (45.8\%) was present among majority of patients, followed by SDH (28.5\%) and EDH (23\%). Midline shift was present among $13 \%$ of patients (Table-3). During the study period $22(6.5 \%)$ patients died. 
Table 3 - CT scan findings among traumatic brain injuries

\begin{tabular}{|l|l|}
\hline Variables & n (\%) \\
\hline Skull fracture & $135(40.1)$ \\
\hline Right & $62(46)$ \\
\hline Left & $53(39.2)$ \\
\hline Bilateral & $16(11.8)$ \\
\hline Midline & $4(3)$ \\
\hline Extra Dural Hematoma (EDH) & $77(23)$ \\
\hline Right & $38(49.3)$ \\
\hline Left & $33(42.8)$ \\
\hline Bilateral & $3(3.8)$ \\
\hline Sub Dural Hematoma (SDH) & $96(28.5)$ \\
\hline Right & $52(54.1)$ \\
\hline Left & $36(37.5)$ \\
\hline Bilateral & $4(4.1)$ \\
\hline Brain contusion & $154(45.8)$ \\
\hline Right & $60(39)$ \\
\hline Left & $50(32.4)$ \\
\hline Bilateral & $35(22.7)$ \\
\hline Midline & $9(5.8)$ \\
\hline Coup brain injuries & $77(23)$ \\
\hline Contre-coup injuries & $35(10.4)$ \\
\hline Midline shift & $44(13.1)$ \\
\hline
\end{tabular}

\section{Discussion}

The current study is conducted in a tertiary care hospital that provides medical service to main city and surrounding villages and districts. In present study about two third of patients were in 3rd-5th decades of life and out of these two thirds were males belonging to the financially productive age group and reflect the vulnerability of this age group and gender for accidents. $[9,4,6,7,10-13]$ There was equal number of patients from urban and rural areas reflecting the proximity of the hospital to both city and surrounding villages. [14] The alcohol consumption was more prevalent male patients and there were more of assault patients (30\%) followed by RTA patients $(26.5 \%)$.as previously reported [15, 16] The same scenario is reflected from our study regarding the time of the day and injury incidence which is commonly reported between 5-9 PM probably these are the peak traffic hours in cities. $[3,7,12,17]$.

In the present study road traffic accidents were the commonest cause of injuries followed by falls and assault and in literature the incidence of injuries from RTAs ranges from 55 to $72 \%$, followed by falls ranging from 20 to $30 \%$ and assaults ranging from 1 to $10 \%$ respectively. [5,18-22]

Most of the incident victims were motorcycle riders (skid and fall) followed by motor vehicle drivers and pedestrian injuries These findigns were similar to the fidnigns reopprted in a a prospective case-study from Eastern China where the authors observed that $61 \%$ of traumatic brain injuries were related to road traffic injuries, of these approximately one-third were motorcyclists, $31 \%$ pedestrians, and motor-vehicle passengers accounted for only $14 \%$. [5] In another study from Maharashtra the studied pattern of fatal vehicular accidents involving head injuries during 2010-2012 and observed that most of the victims were drivers (52.5\%), followed by pedestrian (29.7\%) and passengers (17.8\%). [3]

Another interesting finding in our study was the pattern of fall from height related injuries which involved mainly farmers where the victims were fallen down from coconut tree and the the other common reason was fall from height at construction sites. 
Old people are commonly affected in ground level fall because of age related disabilities they spend most of the time in home where accidental falls are common in home. Fall from tree was next common due to inexperience or weather changes cause alteration in tree texture. A study form US during 2001-2008 and observed a large majority of fall injuries occurred at home (72.8\%), while $15.2 \%$ occurred at locations outside the home. 23 A study found falls from heights were responsible in $48.9 \%$, slipping in bathrooms in $31.9 \%$ and from staircase or ladders in $19.2 \%$. These findings are consistent with our study. In the present study CT findings reports that skull fractures were present in 135(40.1\%) cases and 97 (28.8\%) had base of skull fracture. Studies have reported 34 to $35 \%$ of skull fractures among TBI patients. [13,24] Abnormal intracranial findings were; brain contusion was present in 154(45.8), $\mathrm{SDH}$ in $98(28.5 \%)$ and $\mathrm{EDH}$ in $77(23 \%)$. Studies have reported cerebral contusion ranging from 21 to $53 \%$ $[6,19,25,26]$, high percentage of SDH ranging from 50 to $90 \%[19,27,28]$ and about 10 to $20 \%$ EDH. $[19,27,28]$

In the present study nearly one fourth of TBI patients had associated injuries. Extremities was most common to involve (13.4\%) followed by spine (6.6\%) and chest (3.2\%). Pedestrian injuries from a tertiary institute reported $90 \%$ of associated injuries (new). The current study reported less percentage of associated injuries the reason for the same is not clear. Possibly only TBI patients were referred to the trauma centre. Limitations of the study are; the sample population is limited and sample size is small. Simple statistics is used.

\section{Conclusions}

The three year study from a tertiary centre on TBIs highlights that 3rd, 4th and 5th decade of age group is commonly affected with male predominant. One fourth of injured patients are influenced by alcohol. RTA is a major cause of TBI accounting for $75 \%$, followed by falls and assault. The incidence of head injuries is almost equal in rural and urban areas. Twelve percent of patients are pedestrians. Two wheelers were the commonest vehicle involved in road traffic accidents and the most common mechanism of accident was skid and fall from bike and the commonest victims were motorcycle riders. Home was the commonest place of incidence of fall from height and ground level falls. On CT findings cerebral contusion was most common, followed by skull fracture, SDH and EDH. Death was reported among $6.5 \%$ of patients. Public awareness about TBI consequences and possible preventable measures that can benefit general population is detailed from the demographic and clinical details.

\section{Correspondence}

Dr. Amit Agrawal, Professor of Neurosurgery

Department of Neurosurgery, Narayana Medical

College Hospital, Chinthareddypalem, Nellore-

524003

Andhra Pradesh (India)

Email-dramitagrawal@gmail.com

Mobile- +91-8096410032 


\section{References}

1. Agrawal A, Kakani A, Baisakhiya N, Galwankar S, Dwivedi S, Pal R. Developing traumatic brain injury data bank: Prospective study to understand the pattern of documentation and presentation. The Indian Journal of Neurotrauma 2012;9:87-92.

2. NCRB. Traffic Accidents [online]. Available at: http://ncrb.nic.in/StatPublications/ADSI/ADSI2014/cha pter-1A\%20traffic\%20accidents.pdf. Accessed 2016-1215 15:17:12.

3. Akhade SP, Rohi KR, Dode CR. Pattern of Fatal Vehicular Accidents Involving Head Injuries in Southern Marathwada Region of Maharashtra. MedicoLegal Update 2014;14:206-210.

4. Kumar S, Singh RKP. Pattern of Craniocerebral Injuries in Fatal Vehicular Accidents in Patna (Bihar). Journal of Indian Academy of Forensic Medicine 2014;36:125-129.

5. Puvanachandra P, Hyder AA. The burden of traumatic brain injury in Asia: a call for research. Pak J Neurol Sci 2009;4:27-32.

6. Modi AD. Demographic profile of head injury cases in bhavnagar region, gujarat Amit D. Modi, Amit P. Parmar 2, Vanraj N. Parmar 3, Dharmesh S. Patel 4, Rajanibhai V. Bhagora 5, Jashwant A. Darji 6. Int J Res Med 2014;3:154-157.

7. Dinesh K. Descriptive Study of Head Injury and its Associated Factors at Tertiary Hospital, Northern India. Journal of Community Medicine \& Health Education 2012.

8. Reddy SP, Kumar HN. Retrospective Study of Road Traffic Accident Cases at Harsha Hospital Nelamangala, Bangalore Rural. Indian Journal of Forensic Medicine \& Toxicology 2013;7:193.

9. Pruthi N, Ashok M, Kumar VS, Jhavar K, Sampath S, Devi BI. Magnitude of pedestrian head injuries \& fatalities in Bangalore, south India: a retrospective study from an apex neurotrauma center. The Indian journal of medical research 2012;136:1039-1043.

10. Mishra PK, Singh S. Fatal head injury in homicidal deaths in Bhopal region of central India. International Journal of Pharma and Bio Sciences 2012;3:1103 - 1108.

11. Patil AM, Vaz WF. Pattern of fatal blunt head injury: A two year retrospective/prospective medico legal autopsy study. 2010.
12. Gudadinni MR, Nuchhi UC, Angadi MM. A Study of Road Traffic Accident Cases Admitted in BLDEU'S Shri BM Patil Medical College Hospital and Research Centre, Bijapur. Indian Journal of Forensic Medicine \& Toxicology 2013;7:254-287.

13. Punia RK, Verma LC, Pathak D. Pattern of Fatal Head Injuries in Road Traffic Accidents at SMS Hospital, Jaipur-An Autopsy Based Study. Medico-Legal Update 2014;14:30-34.

14. Prajapati T, Tandon RN. Patterns of Fatal Head Injuries Cases brought to Civil Hospital Mourtuary, Ahmedabad. Indian Journal of Forensic Medicine \& Toxicology 2013;7:209.

15. Kakeri SR, Bagali MA, Goudar ES, Qadri SY. Pattern of injuries and death sustained by the occupants of the two-wheeler during road traffic accidents. 2014.

16. Swarnkar M, Singh PK, Dwivedi S. Pattern of trauma in central India: an epidemiological study with special reference to mode of injury. The Internet Journal of Epidemiology 2010;9.

17. Plunkett J. Fatal pediatric head injuries caused by short-distance falls. The American journal of forensic medicine and pathology 2001;22:1-12.

18. Ahmed A, Mustahsan SM, Tariq F, Abidi SMA, Aslam MO. A Cross-sectional study: Head Injury in Children of Karachi. 2015.

19. Borkar SA, Sinha S, Agrawal D, Satyarthee GD, Gupta D, Mahapatra AK. Severe head injury in the elderly: risk factor assessment and outcome analysis in a series of 100 consecutive patients at a Level 1 trauma centre. The Indian Journal of Neurotrauma 2011;8:7782.

20. Nath PC, Mishra SS, Deo RC, Jena SP. Spectrum of pediatric head injury with management and outcome-A single tertiary care centre study. The Indian Journal of Neurotrauma 2015.

21. Parchani A, Maull KI, Sheikh N, Sebastian M. Injury Prevention Implications in an Ethnically MixedPopulation: A Study of 764 Patients with TraumaticBrain Injury. Panamerican Journal of Trauma, Critical Care \& Emergency Surgery 2012;1:27-32.

22. Saxena MK, Saddichha S, Pandey V, Rahman A. Prehospital determinants of outcome in traumatic brain injury: Experiences from first comprehensive integrated pre-hospital care providers in India: GVK-EMRI Experience. The Indian Journal of Neurotrauma 2010;7:129-133. 
23. Rosen T, Mack KA, Noonan RK. Slipping and tripping: fall injuries in adults associated with rugs and carpets. Journal of injury and violence research 2013;5:61.

24. Khan MK, Hanif SA, Husain M, Huda MF, Sabri I. Pattern of non-fatal head injury in adult cases reported at JNMC Hospital, AM U, Aligarh. Journal of Indian Academy of Forensic Medicine 2011;33:21-23.

25. Ahmad Z, Karmakar RN. An Epidemiological Study of Acute Head Injury and It's Evaluation by CT scan. Journal of Indian Academy of Forensic Medicine 2014;36:173-175
26. Yadav A, Kohli A, Aggarwal NK. Study of correlation between intracranial hemorrhages and skull fractures. Journal of Forensic Medicine and Toxicology 2008;25:42-46.

27. Kumar A, Lalwani S, Agrawal D, Rautji R, Dogra TD. Fatal road traffic accidents and their relationship with head injuries: An epidemiological survey of five years. The Indian Journal of Neurotrauma 2008;5:63-67.

28. Pathak A, Desania NL, Verma R. Profile of road traffic accidents \& head injury in Jaipur (Rajasthan). 2008. 